\title{
Experimental possibilities for industrial ventilation
}

\author{
Florin Rădoi ${ }^{*}$, Ion Gherghe $^{1}$, and Alexandru Cămărășescu ${ }^{1}$ \\ ${ }^{1}$ National Institute for Research and Development in Mine Safety and Protection to Explosion - \\ INSEMEX, 32-34 G-ral Vasile Milea Street, Petroșani, Hunedoara, Romania
}

\begin{abstract}
The activity of evaluation and verification of industrial ventilation installations has a strong preventive role in terms of explosion risk mainly due to the fact that of the three determining elements that can lead to an explosion phenomenon, ventilation installations can determine the presence of two elements namely the presence of fuel (gases, vapours, dusts, mists) and the source of initiation (hot surface, flame, sparks of mechanical origin, electrical sparks, static electricity, etc.). The development of experimental systems on,, which particular hazardous aspects that may occur during the operation of industrial ventilation systems can be studied are vital to avoid dangerous situations in the current operation of ventilation installations. Knowledge of the dynamics of formation of explosive / toxic / asphyxiating environments is achieved by analysing explosive mixtures in relation to specific explosive intervals and is one of the most important priorities in ensuring optimal health and safety at work in industrial activities. The information obtained by analysing the dynamics of the formation of explosive / toxic / asphyxiating atmospheres is extremely useful for personnel responsible for health and safety at work, because with their help relevant decisions can be made to ensure safety and health conditions at the level of industrial premises. The paper presents an experimental equipment usable for the study of industrial ventilation systems.
\end{abstract}

\section{Introduction}

Industrial ventilation is an extremely complex field (Goodfellow H., Tahti E., 2001, Biegert B., Railio J.,2001), that requires deep knowledge of fluid dynamics in the modern computerized version (CFD), three-dimensional heat propagation, complex fluid flow, equilibrium and transient conditions, operating problems, contaminants inside and outside the enclosure, etc.

Industrial ventilation systems are based on execution projects that include systems to prevent and combat risk factors that may occur during the expected technological processes (Cioclea D., Lupu C., Gherghe I., 2013). Based on the in-depth knowledge of the type and quantities of noxious substances that can be released on the premises, the designer provides

\footnotetext{
${ }^{*}$ Corresponding author: florin.radoi@insemex.ro
} 
ventilation installations to limit or eliminate the risk of producing potentially explosive and / or toxic atmospheres.

Based on the design, the manufacturer installs the ventilation systems according to the technical specifications on the intended site.

Depending on the technical specifications, the ventilation systems provided can be with piping or pipeless. Those with pipes can be simple or branched. They can also be equipped with one or more fans (Băltaretu F., Matei I., 1987, Băltaretu R., Teodorescu C., 1971, Matei I., Moraru R., 2000, Teodorescu C., Gontean Z., Neag I., 1980).

During operation, the functional parameters of the fans and the piping have changes that can lead to increased concentrations of gases, vapours, dusts or mists.

In order to avoid the risk of the formation of potentially explosive and/or toxic atmospheres, it is necessary both the development of the experimental capacities and the periodic evaluation and verification of the industrial ventilation installations.

\section{Complex experimental system with variable structure for the study of the ventilation capacity}

Industrial ventilation systems (Bancea O.,2009, Niculescu N., Duţă Ghe., Stoenescu P., Colda I.,1982), are made in a varied and complex range. In order to analyse the behavior of ventilation systems in normal operation or overload, as well as to identify how to sweep the functional parameters related to fans, research is required in the laboratory and in the field in order to prevent the risk of explosion (Cristea A.,1968, Cristea A., Niculescu N.,1971, Cristea A., Terețean. T.Ș.,1976 ).

The complex experimental system with variable structure for the study of the ventilation capacity is intended for the study and experimentation of for the study of the ventilation capacity of closed premises with the risk of forming potentially explosive / toxic / asphyxiating atmospheres (Cioclea D.,2020, Hargreaves D.M., Lowndes I.S., 2007, Oberholzer J. W., Du Plessis J. J. L., 2002).

The overall system is presented in figure no. 1

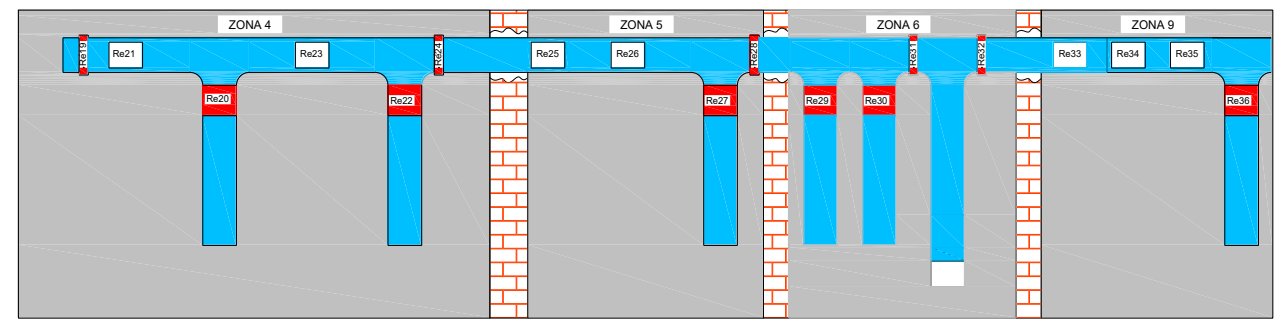

Fig. 1 The overall system.

This experimental system consists of a fan unit - centrifugal motor and a complex structure of rectangular tubing with dimensions of $300 / 400 \mathrm{~mm}$. figures $2 \div 6$.

At the level of the complex piping structure there are 18 flow variators. 


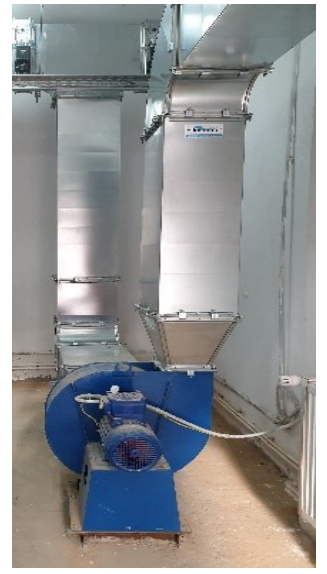

Fig. 2 Motor fan unit.

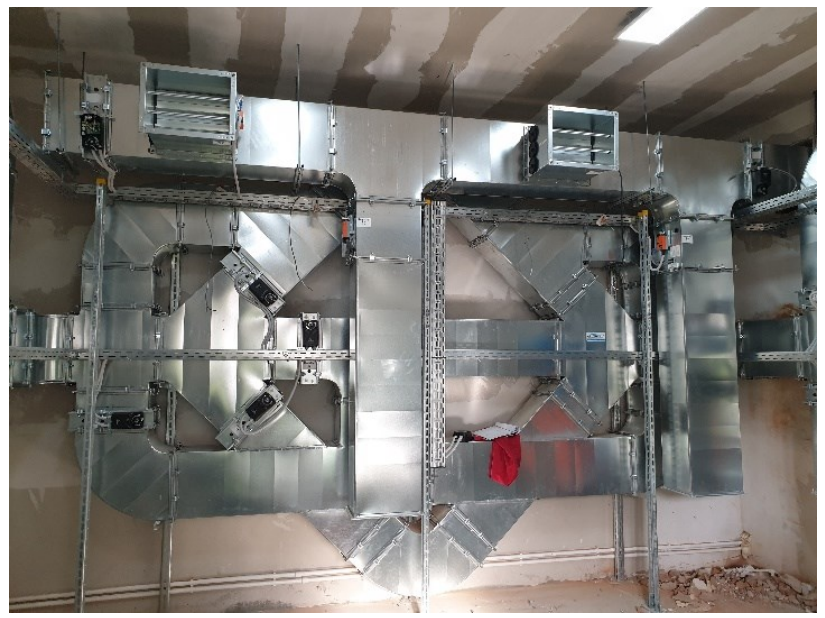

Fig. 3 The structure of the experimentation system from the first room.

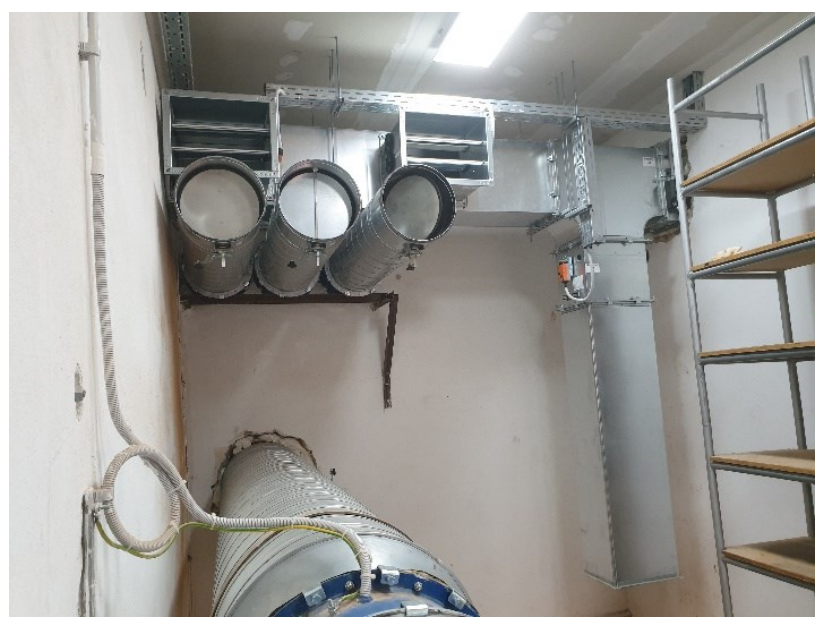

Fig. 4 The structure of the experimentation system from the second room. 


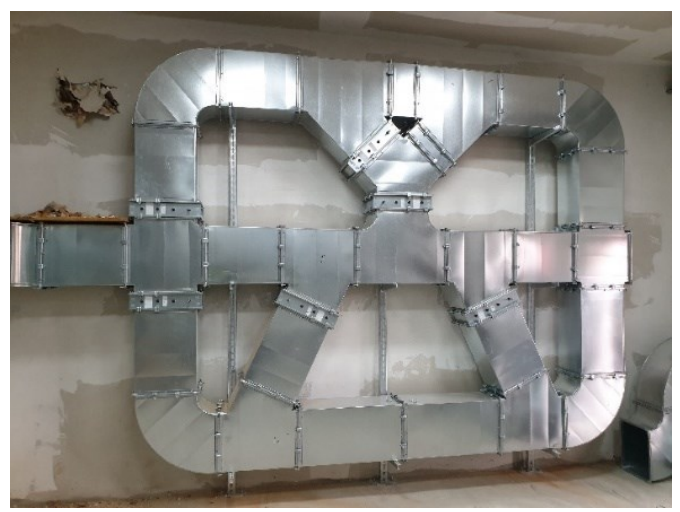

Fig. 5 The structure of the experimentation system from the third room.

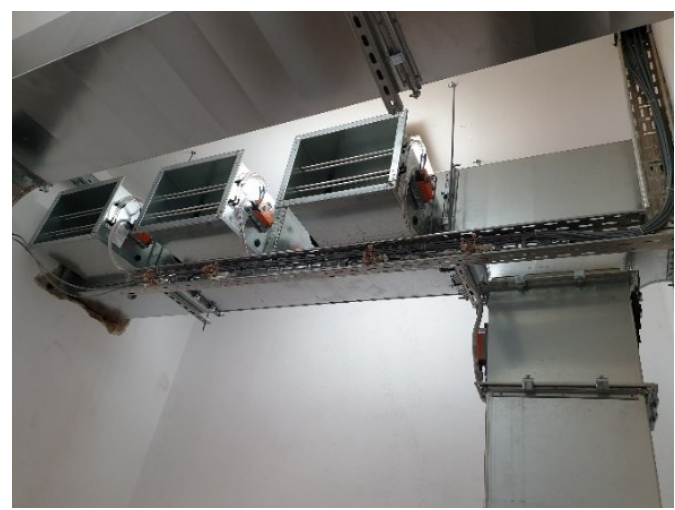

Fig. 6 The structure of the experimentation system from the fourth room.

An automation system is used for the operation of the power equipment fig. 7.

The power supply and automation panel includes protection equipment and frequency converters for controlling the power supply of the fans.

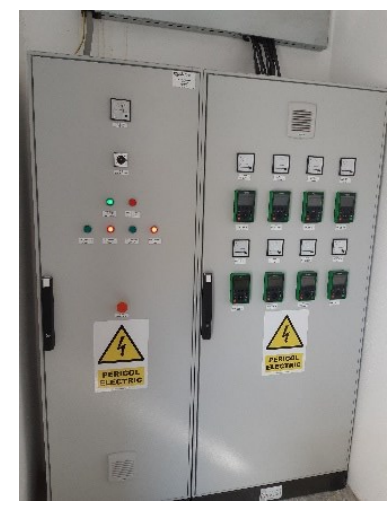

Fig. 7 Automation system.

The automation system of the flow variators is realized with the help of servomotors and the control is realized centrally with the help of a control desk respectively with the help of a SCADA type program, figures 8 and 9 . 


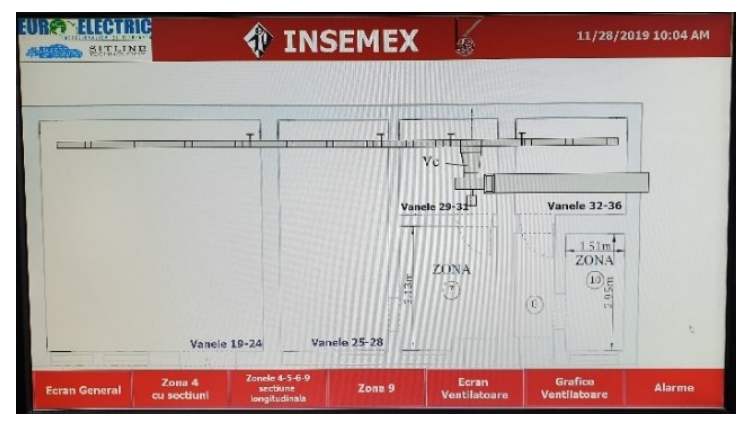

Fig. 8 The SCADA type program.

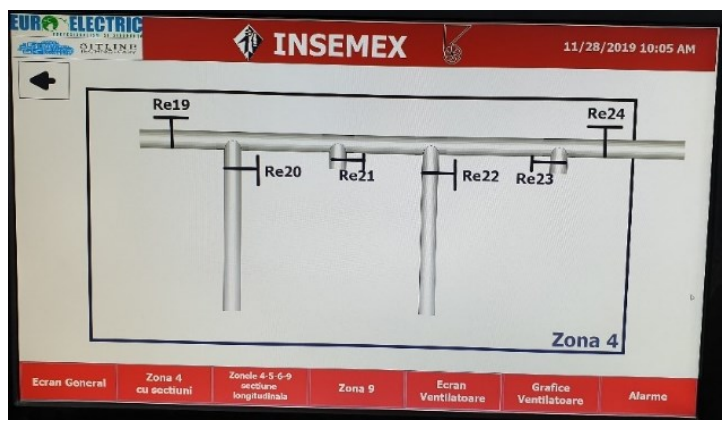

Fig. 9 The flow variator.

An industrial uninterruptible power supply (UPS) is used to protect the experimental system with variable configuration, figure 10 .

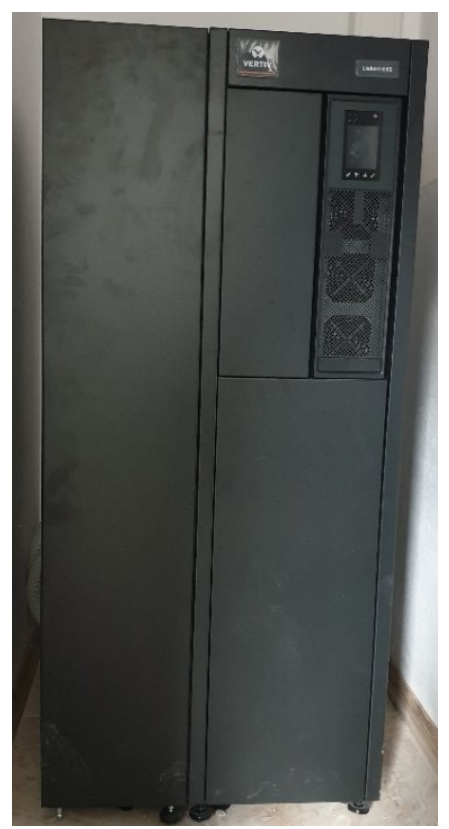

Fig. 10 Industrial UPS. 
This industrial UPS ensures and protects the correct and continuous operation of all equipment in the experimental systems related to the field of industrial ventilation located in the building of the experimental laboratory.

\section{Conclusions}

This paper has highlighted the following findings:

1. The development of experimental systems on which particular aspects can be studied that may occur during the operation of industrial ventilation installations, are useful to avoid dangerous situations in their current operation;

2. In order to cover the needs of experimentation of the ventilation systems usable in closed or semi-closed industrial premises, INCD INSEMEX Petroșani has developed experimental systems within the industrial ventilation laboratory;

3. The experimental systems include the complex experimental system with variable structure for the study of the ventilation capacity;

4. The complex experimental system with variable structure for the study of the ventilation capacity consists of a fan unit - centrifugal motor and a complex structure of rectangular tubing;

5. The experimental system has a switchboard for power supply of power equipment, a SCADA type automation system for the control of flow variators and an uninterruptible power supply (UPS) industrial protection of the all electrically operated equipment.

This paper was developed within the Nucleu - Programme, carried out with the support of ANCSI, project no. PN-19-21-02-04

\section{References}

1. Goodfellow H., Tahti E., Industrial ventilation design guidebook, (Academic Press, San Diego, California, USA, 2001);

2. Biegert B., Railio J., Terminology, Industrial ventilation design guidebook (Academic Press, San Diego, California, USA, 2001);

3. Cioclea D., Lupu C., Gherghe I., Guide for sizing industrial ventilation installations, (in Romanian), ISBN: 978-973-88753-4-0, INSEMEX Research Study, Petroşani, 2013;

4. Băltaretu F., Matei I., Practical guide for the design and verification of partial ventilation installations (in Romanian), Ministry of Mines, Petroleum and Geology, Romania, 1987;

5. Băltaretu R., Teodorescu C., Ventilation and Occupational Safety in Mines (in Romanian), Didactical and Pedagogical Publishing House,Bucharest, Romania, 1971;

6. Matei I., Moraru R., Environmental Engineering and Underground Ventilation, (in Romanian), Technical Publishing House, Bucharest, Romania, 2000;

7. Teodorescu C., Gontean Z., Neag I., Mining Ventilation, (in Romanian), Technical Publishing House Bucharest, Romania, 1980;

8. Bancea O., Industrial ventilation systems, (in Romanian), Polytechnic Publishing House, Timișoara, 2009;

9. Niculescu N., Duţă Ghe., Stoenescu P., Colda I., Ventilation and air conditioning installations, (in Romanian), Didactic and Pedagogical Publishing House, Bucharest, 1982;

10. Cristea A., Ventilation and air conditioning, I, (in Romanian), Technical Publishing House, Bucharest, Romania, 1968;

11. Cristea A., Niculescu N., Ventilation and air conditioning, II, (in Romanian), Technical Publishing House, Bucharest, Romania, 1971;

12. Cristea A., Terețean. T.S.,, Ventilation and air conditioning, III, (in Romanian), Technical Publishing House, Bucharest, Romania, 1976;

13. Cioclea D., Development of techniques and methods to prevent the formation of explosive and / or toxic atmospheres specific to industrial areas, (in Romanian), INSEMEX Research Study, Petroşani, 2020; 
14. Hargreaves D.M., Lowndes I.S., The computational modelling of the ventilation flows within a rapid development drivage, Tunnelling and Underground Space Technology, 22(2), 150-160 (2007);

15. Oberholzer J. W., Du Plessis J. J. L., The Testing of the Strength of Ventilation Structures, Proceedings of the North American/Ninth US Mine Ventilation Symposium, Kingston, Canada, (2002), On line. 